\title{
Hábitos deficientes vs. o problema do "contrato original": notas sobre uma teoria política em David Hume
}

BRuno Simões - UNB

A improvável ideia de uma situação em que um grupo de indivíduos tenha se reunido para fundar a vida política através de um consenso constitui o ponto chave da crítica de David Hume lançada contra a tradição contratualista. Aos olhos de Hume, seria uma desmedida do pensamento considerar, sem nenhuma verificação demarcável na realidade dos povos, que muitas vontades individuais, concorrentes e autointeressadas tenham convergido para unificarem-se em uma só vontade, vale dizer, a vontade soberana. No quadro de uma teoria política discretamente elaborada por Hume em vários de seus escritos, aventar que os indivíduos tenham livremente escolhido a quem eles obedeceriam, ou ainda, remeter a autoridade política a origens divinas, providenciais e irrevogáveis - conforme a doutrina deísta do monarquismo dos Tories -, não é uma associação nem um pouco consequente; além da improcedência do primeiro caso, neste último, o que se conseguiria legitimar é uma excessiva con- 
centração de poder supostamente de origem divina nas mãos de um governante cuja autoridade seria, é claro, incontestável.

Ao contrário dessa especulação, evidências mostram que a formação dos governos se dá a partir da "violência", da aquisição do poder e da manutenção da autoridade por meio da "opinião". São essas, portanto, as linhas mestras do questionamento político humiano dirigido contra as doutrinas contratualistas, que tomavam como problema filosófico-político a análise das causas constitutivas do governo, com a pretensão de assim fundamentar racionalmente o governo justo.

Bem ou mal, a autoridade já se mostra estabelecida. E a evidência de que assim ela foi sendo exercida, desde seus primórdios, é para Hume irrecusável. Na abertura do ensaio "Dos primeiros princípios do governo" (1741), o filósofo assinala que a vida social (os human affairs) está calcada numa "implícita submissão", em que uma maioria é governada por uma minoria seleta, em que os homens abdicam de "seus próprios sentimentos e paixões em favor dos de seus governantes". Isso ocorre, explica o autor, por conta do papel da "opinião" da maioria acerca da minoria: seja no caso da Constituição da Inglaterra, em que a maior parte das terras usurpadas se destina, com "autoridade válida", apenas a poucas pessoas; seja ainda em relação ao "medo da tirania", pois na força física do líder jamais poderia se encontrar a razão da submissão popular: a opinião manifesta de diversas formas sua eficácia persuasória. De modo que, até aqui, o que se pode tomar como fundamento do governo reside na concentração de poder reunida numa autoridade política, que, uma vez consolidada, constitui o próprio signo de aceitação popular da ordem instaurada e mantida (Hume, 1980, pp. 243-244).

Num sentido concreto, a obediência à autoridade de um "novo 
governo" se dá mais por "medo e necessidade" do que por uma subordinação voluntária que seguiria de bom grado as determinações do governante contando com "qualquer ideia de fidelidade ou de obrigação moral" (Ibid., p. 235). Ao sofrer as pressões de um monarca usurpador, o povo se habitua ao poder que o submete, sendo levado pouco a pouco a aceitar, como seu líder legítimo, quem apenas se apoderou da administração da vida pública - o pressuposto a origem do governo dispensa a ideia de que o indivíduo tenha, em algum momento, escolhido a quem ele obedeceria.

Nesse quadro, o hábito será um catalisador para a submissão popular. E, sem dificuldade, o conhecimento das questões políticas implica nessa condição submissa; de modo que, quando impelido por uma "curiosidade" sobre as causas da obediência ou sujeição, "logo que ficam sabendo que eles próprios e seus antepassados têm estado sujeitos, desde há várias épocas ou desde tempos imemoriais, a certa forma de governo ou a certa família, imediatamente concordam, reconhecendo sua obrigação de fidelidade". Na própria realidade dos povos, assinala-se o fato de os indivíduos se acostumarem, na esteira de seus ancestrais, a se submeter ao governo, conformando seus "laços de obediência" (Ibid., pp. 232-233). E mesmo que tal conhecimento passe a exigir o consentimento popular como justificativa da aceitação da estrutura política consolidada, historicamente isso só chegou a tal termo devido a um longo processo de dominação, entremeado de força e do uso permanente da persuasão sobre a mente do povo.

Em vez da concepção contratual de Hobbes e de Locke (em que haveria, cada qual ao seu modo, uma espécie de momento estanque delimitado entre o abandono do estado de natureza e 
a inauguração da ordem civil), o estabelecimento da autoridade política em Hume se dá num sentido bastante elementar. Primordialmente, a força e as adversidades desencadeadas a partir daí impõem-se como uma cena primitiva, que se desdobra em todo o processo de estabelecimento e manutenção do poder político. Mas se não houvesse nesse processo o convencimento de que o governante deve ser obedecido pelos seus méritos enquanto tais, nenhuma autoridade lhe seria reconhecida, por mais invencível que fosse a sua força. Hume indica uma predisposição social a "sacrificar suas vidas e fortunas para a manutenção da justiça pública", reiterando a ideia de "dedicação de todos povos a seus antigos governos" (Ibid., p. 243). No interior dessa submissão, porém, deve-se frisar: não há aí nenhuma moralidade em favor da realização de uma ordem política perfeita; pois, observa Hume, tanto em relação a um partido faccioso, que age por interesses inescrupulosos, como a uma diretriz partidária correta e justa, a relação de lealdade dos indivíduos, apoiando a permanência da autoridade, leva em conta as vantagens daí advindas.

No ensaio publicado postumamente "Da origem do governo" (1777), Hume destaca os fatores que "forçam o homem a preservar a sociedade" nas suas "relações mútuas" (mutual intercourse) que, de certa forma, são um desdobramento do fato de ter "nascido em uma família", quais sejam: a "necessidade", a "inclinação natural" e o "hábito". Num cenário acidental, frágil e irregular, mais uma vez o hábito responde pelo aperfeiçoamento daquilo que a natureza estabeleceu imperfeitamente: "O governo se inicia de maneira mais casual e imperfeita" (Govern- 
ment commences more casually and more imperfectly). Quanto à sociabilidade humana, postula-se uma imperfeição inata, mais manifesta nos integrantes de "tribos selvagens". E Hume reforça sua hipótese já considerada anteriormente: o começo da ordem política se deu pela força de um homem com "coragem" e "gênio" que conseguiu, em meio às imperfeições do "estado de guerra", se tornar mais "visível"; e que, dados "os efeitos perniciosos da desordem", adquiriu supremacia sobre as multidões (the first ascendant of one man over multitudes begun during a state of war) (Hume, 1980, pp. 229-230). Encontra-se aí uma espécie de levantamento de dados e fatores variados que denunciam, na própria complexidade de sua exibição, a dificuldade de se pensar que a razão por si só possa dar conta de todas as etapas desse processo político.

A "necessidade" de se "preservar" a sociedade e de a ela se submeter assume total relevância na medida em que as "perniciosas consequências da desordem se revelam mais fortemente". Num misto de "força e consentimento", a violência do líder agride os que se lhe subordinam, embora, conforme a "equidade, prudência e valor" de sua investida, a autoridade que ele conquista assinale o próprio resultado da aceitação social (Ibid., pp. 229230).

O recurso do autor à sensibilidade humana (os efeitos produzidos pela violência daquele que se lança sobre a multidão) é soberano, dispensando qualquer argumentação que justifique racionalmente a superação da discórdia: no começo, a força é mais presente e manifesta, em conformidade com a desordem reinante; aos poucos, consolidando-se a autoridade, os indivíduos simplesmente já se encontram subordinados. Em outras palavras, em vez de uma razão regrada por ditames e leis de 
natureza, que supostamente indicariam o caminho da mudança em uma conturbação social, Hume delineia um processo de amadurecimento que, em meio às imperfeições humanas, desenvolve uma ordem civil a fortiori. A partir de uma espécie de adestramento humano, vai se estruturando um equilíbrio na "guerra intestina de todos os governos", que se remete em última análise à disputa permanente entre "autoridade e liberdade", não podendo uma prevalecer em definitivo sobre a outra, donde a equação humiana: não há governo que subsista sem que o povo se lhe subordine, ou seja, sem que se considere o aperfeiçoamento da opinião da sociedade sobre o "direito de dominar" do governante; por outro lado, não há autoridade que se mantenha como tal se o seu poder não for limitado, aliviando seu jugo sobre a sociedade. Mas, entre a liberdade, que é "a perfeição da sociedade civil", e a autoridade, "essencial para a existência" social, Hume não hesita: a primazia é da autoridade, como fonte da garantia do "vasto mecanismo de nosso governo" e recurso constante em vista do aperfeiçoamento da opinião a seu respeito. Nessa medida, a interdependência entre a autoridade do governante e a obediência do súdito desenvolve-se segundo a prática da convivência que precisa ser ordenada e pacífica, isto é, cujos motivos da organização são "imperiosos e evidentes", permitindo nos ordinary cases dos indivíduos - nos caminhos que seus "antepassados constantemente trilharam" (trod) - o reconhecimento da importância da "administração imparcial da justiça" para o "progresso da sociedade" (Ibid., p. 230).

Ora, tudo pareceria bem encaminhado a uma forma adequada de os homens viverem reunidos e a aperfeiçoar suas disposições naturais, não fosse a "fragilidade e perversidade de nossa natureza" que leva o indivíduo a nem sempre seguir a justiça e a 
obedecer a ordem civil. Tal "fraqueza" (weakness) da natureza humana é incurável, entende Hume, pois sempre será possível considerar a vantagem obtida individualmente pela fraude, que é maior do que o prejuízo que tal ato repercute sobre a sociedade: os "princípios da natureza humana" por vezes fazem com que tendamos mais à "paixão do poder" do que ao "nosso dever para com outros cidadãos". Em contrapartida, por serem mais "longínquos" os interesses verdadeiramente importantes, que garantiriam benefícios públicos, eles perdem visibilidade diante do "fascínio (allurement) exercido por tentações frívolas imediatas". Decerto, essas falhas crônicas do indivíduo podem ser remediadas pelos efeitos "paliativos" da justiça. Mas, para que a lei se cumpra, será preciso lançar mão da tendência aos interesses imediatos, combatendo-os seja pela punição dos que violam a lei, seja pelo enaltecimento dos méritos do bom governante, afirmando sua autoridade e a de seus sucessores. Há aqui um papel, por assim dizer, reformador da justiça e do dever de obediência, este último, diz Hume, "inventado para sustentar o [dever] da Justiça". No interior de um entremeado alternante e fugaz de desejos particulares de cada um - insustentáveis por si sós na coletividade -, desdobra-se, pela "punição" dos transgressores e "recompensa" dos justos, uma atividade reflexiva e reparadora, que lida com o comportamento passional e refratário dos indivíduos, forçando-os, pois, a "consultar seus interesses verdadeiros e permanentes" (Ibid., p. 231)1.

\footnotetext{
${ }^{1}$ Rolf Kuntz, em "Hume: a teoria social como sistema", delineia um importante quadro comportamental acerca das limitações do indivíduo desprovido das regras de convenção e do estabelecimento da justiça: "O indivíduo descrito por David Hume tem outras limitações importantes. Seu mundo afetivo e moral corresponde a uma série de círculos concêntricos. $\mathrm{O}$ cosmopolitismo é tão pouco provável nesse universo quanto no rousseauniano.
} 
No ensaio "Do contrato original" (1748), Hume observa que a história mostra uma longa alternância de conquistas e derrotas de governantes que, afirmando o seu "direito independente à soberania", ascendem ao (ou são destituídos do) poder político por meio da "força, da violência e da usurpação"; dificilmente a hipótese de um contrato original resistiria a essa permanente e conturbada passagem dos tempos (Ibid., pp. 232-233). Na obediência pura e simples, não se constata nenhuma semelhança com a ideia contratualista de um "consentimento voluntário" estipulado pela razão de homens livres e iguais, pois o vínculo de nossa submissão à autoridade relaciona-se aos "interesses e necessidades da sociedade humana" que, no final das contas, são uma mera contrapartida, que sugere uma moralidade ("justiça", "lealdade", "fidelidade") a esses seres imperfeitos, que, se deixados à mercê de seus "instintos primitivos", agiriam tão-somente no sentido de "conceder a [si] mesmos uma liberdade ilimitada, ou a procurar o domínio sobre os outros". Um mínimo de experiência bastaria para mostrar os "efeitos perniciosos" do desvario da desordem a que nos expomos quando vivemos sem a

Mais que isso: a benevolência tende a esgotar-se muito antes de atingir os limites de cada sociedade política. A atração entre os sexos, o cuidado da família e a atenção aos próximos esgotam a capacidade natural de se interessar pelos outros. O interesse de cada homem por si e por um círculo restrito de pessoas impediria a vida em grandes sociedades, se nenhum fator interviesse para controlar a inclinação natural dos indivíduos. A parcialidade e a afeição desigual devem não só influenciar o comportamento em sociedade, mas também moldar as ideias de vício e virtude. Levados apenas por essa inclinação, os homens nunca chegariam a se agrupar em grandes conjuntos. Também não conseguiriam, portanto, reduzir o risco de conflitos em grau suficiente para desfrutar de razoável segurança, e ultrapassar as mais primitivas condições de vida" (Kuntz, 2011, p. 464). 
sucessão regular de autoridades, obedecidas de forma "rigorosa", afastando os indivíduos de seus interesses imediatos e, por assim dizer, convidando-os a perdurar em meio à civilidade.

A natureza humana, desde sempre balizada por alguma convivência social, não se resolve na concepção de um indivíduo racional, autônomo, ciente de seus desejos e dos meios para satisfazê-los, que livremente se engajaria na criação da ordem social, erigindo o Estado do qual fará parte e que melhor condiz com seu raciocínio. O tempo, propulsor de contínuas mudanças, impede que se possa "pretextar o livre consentimento ou a sujeição voluntária do povo" (without any pretence of a fair consent, or voluntary subjection of the people) (Hume, 1980, p. 233). A reunião de forças numa ordem política resulta, pois, de uma combinação de procedimentos, de determinações de padrões de conduta, que resultam da importância adquirida do cumprimento dos compromissos para "o comércio e as relações entre os homens" - prescindindo, portanto, de qualquer livre consentimento do qual derivaria a obediência voluntária à autoridade (cumprimento sem o qual seria "totalmente impossível viver em sociedade, ou pelo menos numa sociedade civilizada, sem leis, magistrados e juízes para impedir os abusos dos fortes contra os fracos, dos violentos contra os justos e equitativos"). Em outras palavras, na opinião sobre os "benefícios" do governo, expressa-se a "convicção" de que qualquer regime político, contanto que detenha a "força em suas mãos", pode ser vantajoso para os "interesses e necessidades gerais da sociedade" (Ibid., p. 237). Quanto ao que os contratualistas alegam sobre o artifício da criação da autoridade da ordem soberana, implementando-o como pura e simples criação racional, Hume, por entender que tais doutrinas conduzem a "paradoxos que repugnam aos senti- 
mentos mais comuns dos homens e aos usos e opiniões de todas as nações e de todas épocas", recomenda que "esses filósofos passeassem seu olhar pelo mundo inteiro", por meio do que "nada encontrariam que tivesse a menor relação com suas ideias" (Ibid., p. 232, 240).

A utilidade da manutenção da ordem política permanece irretocável: para a ordem firmada pelo governante converge toda a autoridade política, que articula os interesses públicos e privados da sociedade civil. Ao longo de contínuas mudanças históricas, o comando originalmente arbitrário de quem usurpou o poder adquire muito mais regularidade e aceitação de um povo domesticado do que a momentânea fundação política pretendida através do contrato original. O contraponto entre a ação promíscua de um particular e a sua insustentabilidade pública abre espaço para que o "verdadeiro interesse" do indivíduo passe a residir no motivo pelo qual ele deve obedecer. A convergência deste com a realidade do poder político bem administrado se dá enquanto fato socialmente experimentado; e o comprometimento da instituição política com demandas sociais (paz e segurança) e desejos individuais (estabilidade das posses) redunda no aprimoramento da convivência humana. Frente ao benefício do interesse geral que o governante promove, o desejo de cada um (ou o conhecimento imperfeito que o indivíduo tem de suas paixões) torna-se de pouca monta; no esteio da submissão à ordem e do cumprimento da justiça, o próprio indivíduo conseguirá viver melhor.

Mesmo que por vezes a natureza humana pareça operar em Hume com propósito semelhante ao da concepção contratualista - vale dizer: subsidiar uma unidade primordial para a fundamentação teórica de um sistema político -, ela é apresentada como pura atividade, exercendo seus interesses enviesados pelas 
paixões, e não como uma essência ou conjunto de atributos intrínsecos que, com certa pureza, estariam isentos dos tropeços da natureza ou de acidentes de percurso. Na condição de resultado de determinações dos mais diferentes tipos, e lastreado pelo hábito, o indivíduo sofre os efeitos do poder do governante, razão pela qual toda a história política vai sendo traçada. Tendo por base aquilo com que os indivíduos se acostumaram a viver, noções caras aos contratualistas, como "reta razão", "lei natural" e sobretudo "consentimento" - que permitiriam estabelecer uma fonte incontroversa da forma justa, legítima e certa de se governar e de ser governado - prestam-se apenas a confusões explicativas. Se Hume concede parcialmente o pressuposto contratualista de uma sociabilidade adquirida (não sendo, pois, um atributo imediato da natureza), ainda assim isso não permite abraçar a hipótese de um estado de natureza composto seja de indivíduos hobbesianos irascíveis, inseguros e em conflito, ou de criaturas lockianas, criptocidadãos, detentores, antes mesmo do estabelecimento da ordem civil, de bens que o governo não poderá violar. Prevalece em Hume a ideia de uma debilidade da natureza humana que dificilmente poderia ser contornada.

$$
* * *
$$

Em vez do consentimento contratual, o ponto de partida político de Hume está no fato elementar de que o indivíduo nasce em família, primeiro traço de sociabilidade e submissão. Inicialmente, há a experiência do pequeno núcleo da family-society, diz Hume no já mencionado ensaio "Da origem do governo" e na Investigação sobre os princípios da moral (1751). Já nesse estágio, o indivíduo age no sentido de saciar seus desejos particulares e descobrir vantagens que ultrapassem os limites de convivência 
inicial, percebendo a importância do aumento de relações e, por fim, do "comércio" e da sociedade. Parte-se assim de paixões primárias (prazer e desprazer) para ingressar num contexto mais elaborado, em que se julga, primariamente, por meio de regras partilhadas em família, a moralidade ou imoralidade do ato com vistas a aprová-lo ou a puni-lo e reajustá-lo (Id., 1995, p. 44).

Nesse quadro, surge a possibilidade de uma tomada de consciência (ou de "reflexão") de que a vida em sociedade - na qual se vive, em alguma medida, desde sempre - representaria um benefício para a estabilidade das aquisições de cada um. O acúmulo de posses também pesa na balança da opinião e na permanência da ordem instituída; de modo que o comportamento interessado dos indivíduos se desdobra na adesão a regras de justiça, permitindo que esta alcance certo grau de consolidação geral, com a garantia da paz e da propriedade dos bens materiais. Embora Hume trate a justiça como um artifício da invenção humana ${ }^{2}$ (e não como uma das virtudes naturais mais elementares, como a "benevolência"), sua convenção é dita "naturalmente aprovada": os deveres morais passam a ser naturalmente cumpridos na medida em que proporcionam satisfação - satisfação essa indireta, é verdade, pois segue a orientação geral da convivência pacífica, cujos benefícios para os desejos individuais não são imediatos, mas, ainda assim, uma satisfação, sem a qual nenhum interesse teria vez.

Pela invenção da justiça um sofisticado desvio do imediatismo da satisfação das paixões vai se delineando. O sistema de regras, mesmo que retarde e, em muitos casos, contrarie os interesses

\footnotetext{
${ }^{2}$ Sobre as diversas acepções do termo "natural", cf. Hume, Tratado da natureza humana $3,1,2$. Sobre a concepção de justiça como virtude "natural ou artificial", cf. idem, ibidem 3, 2, 1.
} 
de cada um, firma-se porque através dele e do seu cumprimento em maioria se obtém, reflexivamente, o benefício da paz. Contudo, o motivo da convenção e estabelecimento das regras de justiça continua sendo o interesse primário do indivíduo, não a benevolência natural que, num espectro social mais amplo, não teria eficácia.

Com efeito, a ação justa contraria o quase irresistível egoísmo das motivações do indivíduo, atuando como uma recomendação: no que diz respeito às necessidades e interesses de cada um, e tendo em conta a possibilidade de perda de aquisições, o cumprimento das convenções de justiça oferece um risco menor. Da experiência reiterada dessa realidade, deriva a crença no bem e a consciência dos benefícios trazidos pela utilidade pública ${ }^{3}$.

Contando a justiça com essa base empírica, sua manutenção pode não ocorrer, todavia, numa sociedade mais numerosa, onde o prejuízo causado pelo descumprimento das regras é menos visível, donde os constantes abalos na crença na justiça: perdese de vista o motivo pelo qual os indivíduos zelam pelas regras de convivência, e torna-se necessária a criação de um novo artifício, o governo.

Como se vê, mesmo no estabelecimento da autoridade política, as regras de justiça dependem de uma vivência anterior das paixões, não de uma abrupta instituição racional e contratual capaz de determinar as noções de certo e errado. De fato, o que se mostra como "interesse público" consiste numa modalidade

\footnotetext{
3'Se 'convenção' quer dizer um sentimento de interesse comum, um sentimento que cada qual experimenta em seu próprio peito, que observa em seus companheiros e que o leva, em colaboração com os outros, a estabelecer um plano ou sistema geral de ações que tende à utilidade pública, deve-se confessar que, neste sentido, a justiça surge de convenções humanas" (Hume, 1995, p. 201).
} 
diferente das inclinações naturais. No entanto, tal ampliação reflexiva do interesse não se esquiva dos desejos individuais de cada um, isto é, não ignora a tendência individual à própria satisfação. A diferença, porém, é que a estabilidade civil politicamente promovida não é direta nem propriamente prazerosa; os efeitos benéficos da sua instituição - progressivamente percebidos como benéficos - é que justificam uma acomodação geral à realidade, em que a satisfação de prazeres se insere num quadro de obediência. A sociedade politicamente organizada é estabelecida por conta das garantias de satisfação de interesses que, ao mesmo tempo, dependerão das habilidades e articulações do governo para com a sociedade civil.

Viver numa sociedade governada por um líder político se torna cada vez mais a forma segura de garantir as posses de cada um, o que exige, em contrapartida, evitar danos e absterse dos bens alheios - e até aqui não estaríamos tão distantes de um pano de fundo cerzido por um Hobbes ou um Locke. Num sentido intrínseco, o interesse individual que, ao agir sem medir as consequências, põe em risco a convivência, é o mesmo que, sob os efeitos punitivos da justiça, motiva a conservação da sociedade - decorrência essa que retira tal pano. Portanto, para tornar-se obrigatória, a justiça tem de se resolver em sua utilidade pública, isto é, na busca da conservação e realização de interesses individuais progressivamente inscritos num contexto político de subordinação e convivência pacífica ${ }^{4}$.

\footnotetext{
${ }^{4}$ Não à toa, no ensaio "Da obediência passiva" (1742), Hume sintetiza o caráter útil da justiça sem, entretanto, conferir-lhe um peso irrevogável, uma vez que, em casos extraordinários, admite a resistência dos súditos: "A obrigação da justiça se funda inteiramente nos interesses da sociedade; interesses que exigem um respeito mútuo da propriedade a fim de salvaguardar a paz entre os homens. Se a execução da justiça implicar consequências
} 
Como foi dito, os bons atributos do governante lhe conferem autoridade; o reconhecimento de sua prudência e o equilíbrio de seus atos administrativos evitam que desmesuras políticas venham a acarretar no descumprimento das leis e na insurgência popular. No limiar entre a manutenção do poder e a iminência de ruptura, o motivo da conservação vincula-se à obediência, permitindo derivar, sem expedientes racionais, a obrigatoriedade do cumprimento das regras. "O tiranicídio", observa Hume, "torna os tiranos ainda mais impiedosos". Na balança políticosocial, a "rebelião" dos súditos é perniciosa não pela dissolução da instituição política, que, dependendo do contexto, pode ser inevitável, mas sobretudo pelas "medidas violentas" que o governante pode vir a tomar em represália. A obediência, portanto, se sustenta pelo resultado prático de que está investida a relação entre governante e súditos (Id., 1980, p. 241).

$$
* * *
$$

A Investigação sobre os princípios da moral considera que "somos naturalmente parciais para com nós mesmos e para com nossos amigos, mas somos capazes de compreender a vantagem resultante de uma conduta mais equânime" (Id., 1995, p. 42). Se, por um lado, ser parcial em relação aos outros e a si mesmo é irresistível, por outro, um desdobramento reflexivo se faz presente a partir dessa consideração. Na conclusão dessa

altamente perniciosas, essa virtude deve ser suspensa em circunstâncias extraordinárias pela utilidade pública" (Hume, 1980, p. 241 - tradução modificada). O original traz: "as the obligation to justice is founded entirely on the interests of society, which require mutual abstinence from property, in order to preserve peace among mankind; it is evident, that, when the execution of justice would be attended with very pernicious consequences, that virtue must be suspended, and give place to public utility, in such extraordinary and such pressing emergencies" (Hume, 1985). 
Inquiry, Hume entende que a abrangência do sentimento de humanidade ("sentiment of humanity" ou "affection of humanity") (Ibid., pp. 156-157) ultrapassa a particularidade passional naturalmente parcial, apontando para aquilo que "toda sua audiência irá com ele compartilhar". Ao contrário da radicalidade da hipótese egoísta que, em relação a nossas "ideias mais imparciais", diz Hume, "exige um imenso contorcionismo filosófico", o sentimento de humanidade possibilita uma acomodação às regras de justiça criadas, de fato, num cenário de plena parcialidade e busca de vantagens, mas cujo resultado se mostra imparcial para a ordem pública. No estabelecimento da justiça, conta-se reflexivamente com o sentimento de humanidade ensejado em cada indivíduo à medida que a brutalidade de suas paixões vai sendo refinada. A "reflexão" e a "resolução", bem como os efeitos punitivos da lei, são fundamentais para que o imediatismo dos desejos sofra uma atenuação; processo esse que se dá no próprio interior do hábito da submissão que, graças à ordem pública, pode levar o indivíduo a exercitar suas habilidades e adquirir uma "firmeza de caráter" frente à força das suas paixões.

Como se nota, a acepção de artifício em Hume é bastante peculiar, se comparada à dos contratualistas. Não se trata mais, como em Hobbes, de estipular meios para realizar desejos e escapar de grandes perigos; nem de buscar, como em Locke, algum conforto para a "inquietude" (uneaseness) de nossas práticas parciais. A campanha moderna contra o aristotelismo (o inatismo da sociabilidade humana) conseguiu de fato levar à vigência uma concepção desnaturalizada, segundo a qual a convivência é um modo de ser (adquirido) para se viver melhor, seja pela concentração hobbesiana de autoridade do poder controlador do soberano, seja pela organização lockiana da sociedade civil em 
defesa da propriedade, ambas garantindo o cumprimento da lei; donde, portanto, o surgimento de um protótipo de sociedade fundamentado numa razão destacada da realidade, erigindo o Estado por meio de um pacto que determina racionalmente o horizonte político que regula a realidade social ${ }^{5}$.

Todavia, Hume não pensa a sociedade por contraposição a um estado de natureza, nem pretende, com o artifício do Estado, superar racionalmente o domínio da paixão, para acomodar os interesses individuais. Mesmo admitindo o artifício da justiça e a tutela soberana do governo como elementos imprescindíveis a uma coletividade mais segura e confortável, Hume dispensa a questão de uma legitimidade originária para o poder político (a bem dizer, a todo instante ele no mínimo sugere que tal origem não foi nem um pouco legítima).

Em todo caso, reflexivamente, a modulação das paixões auxilia, modera e abranda a parcialidade da conduta humana. Mas,

\footnotetext{
${ }^{5}$ Deve-se levar em conta que em Hobbes e Locke o pacto encontra sua fundação nas leis de natureza (determinadas, em última análise, por Deus), como ditame da razão que estabelece as regras de convívio. Para esses contratualistas - respeitadas as diferenças entre eles -, o artifício do contrato antecede a validade de qualquer outra construção racionalmente humana, mesmo que haja, por exemplo, em Locke, uma fundação moral, por vezes tratada como ontológica, da propriedade, antes mesmo do estabelecimento do Estado. Nesse projeto moderno, há no fundo uma radicalidade política que consideraria que o que faz parte da vida em sociedade começa contratualmente como que do zero. Sem sequer olhar para trás, a ordem política racional surge presumindo-se um abandono, ou mesmo um aniquilamento, do tendencioso estado de natureza. De todo modo, mesmo que os contratualistas não se prendam à existência histórica de tal estado (tratando-se unicamente de uma hipótese racional que justifica a existência e a necessidade do governo), no Tratado da natureza humana Hume considera essa concepção racional do estado de natureza "como uma simples ficção, não muito diferente da ficção de uma Idade de Ouro, inventada pelos poetas" (Hume, 2009, p. 534).
} 
para que tal processo se justifique, o pano de fundo da argumentação de Hume se vale de uma prática social que, de início, incita e, aos poucos, regra as paixões. Em outras palavras, de um indivíduo isolado permanentemente em conflito com seus semelhantes não decorre uma prática que sustente a conjunção de vontades individuais na vontade geral de um pacto, haja vista a necessidade de um mínimo de entendimento coletivo. Seja um pacto expresso, como em Hobbes, ou que comporte a possibilidade de um acordo tácito, racional e legal, como em Locke, a radicalidade com que esses teóricos contratualistas conceberam o estado de natureza parece, do ponto de vista de uma teoria política, inviabilizar a própria concepção da vida em sociedade, não sendo possível sequer vislumbrar - senão à luz de um "consentimento" rechaçado por Hume - o momento em que o indivíduo se submeteria, de bom grado, ao poder político, conforme se nota com certa ironia a noção de "livre consentimento" no ensaio "Do contrato original": "Seria o mesmo que dizer que um homem, devido ao fato de permanecer num navio, dá seu livre consentimento à autoridade do capitão, embora tenha sido levado para bordo enquanto dormia, e só lançando-se ao mar e morrendo possa sair do navio" (Id., 1980, p. 235) ${ }^{6}$.

\footnotetext{
${ }^{6}$ Do ponto de vista institucional, o consentimento torna-se ainda mais incompatível com a formação de um governo: "É inútil dizer que todos os governos são ou devem ser criados com base no consentimento popular, na medida em que a necessidade das coisas humanas o permitir. Isto é totalmente favorável à ideia que defendo. Afirmo que jamais as coisas humanas permitirão tal consentimento, e raramente algo que aparente sê-lo; e a conquista ou a usurpação, ou mais simplesmente a força, mediante a dissolução dos antigos governos, são a origem de quase todos os novos governos que o mundo viu nascer. Nos poucos casos em que possa parecer ter havido um consentimento, este foi geralmente tão irregular, tão limitado ou tão misturado com a fraude e a violência, que não se lhe pode atribuir
} 
Para Hume há um exagero entusiasta nas extravagâncias conceituais do contratualistas que culmina na ideia aberrante do consentimento. Nada mais improvável do que uma vontade livre que consinta justamente no momento de "estabelecimento de um novo governo", período esse de profundas conturbações, em que predomina tão somente a "força militar e a habilidade política", onde os que supostamente consentem - à maneira do homem lançado no navio - o fazem apenas por falta de alternativa, isto é, sem nenhuma liberdade. Nunca houve muito espaço na realidade para essa ação deliberada do indivíduo que, ao abandonar seu "direito natural sobre todas as coisas", na expressão de Hobbes, daria um voto de confiança à instituição política: todos os indivíduos já nascem sob um governo, sem muita possibilidade de se "livrarem" dele.

\section{$* * *$}

Mas não se pode ignorar o modo como Hume descredencia esse consentimento, que se refletiria na vontade geral de semblante democrático, talvez não muito inspiradores à época, a ponto de ele menosprezar o fato de o regime democrático ser a "única fundação legítima de todo governo". Segundo o filósofo escocês, "não é de esperar grandes descobertas" num processo democrático, e arremata:

Que coisa é essa tão louvada, a eleição? Ou é uma combinação de alguns grandes homens, que decidem por todos e não permitem oposição alguma, ou é o furor de uma multidão que segue um sedicioso cabeça de motim, que talvez não seja conhecido por uma dúzia de entre eles, e deve o lugar que ocupa apenas à grande autoridade" (Ibid., p. 234). 
própria impudência ou ao capricho momentâneo dos seus companheiros (Ibid., p. 233).

Nessas novas e conturbadas resoluções políticas e reações sociais, talvez esteja em jogo a própria emergência de uma forma de se fazer política que - através de "inovações violentas" e "perigosas", vaticina Hume, "mesmo quando feitas pelo legislativo" (Ibid., p. 236) ${ }^{7}$.

O descompasso entre ordem política e sociedade leva à destruição da ordem pública, ou do Estado como um todo, que, por força das circunstâncias, é substituído por uma nova ordem, que passa a depender cada vez mais do consentimento dos súditos. De fato, o povo nunca viveu uma realidade contratual elaborada segundo um sistema racional. Ainda assim, o que começa a surgir é a própria maneira inusitada (e não mais habitual) pela qual passa-se a obedecer à autoridade.

Ao descredenciar a convergência de muitas vontades individuais na unificação de uma vontade popular; ao frisar a impossibilidade de "o conjunto do povo" ter condições de escolher o "novo regime"; em suma, ao considerar que, dadas as falhas da natureza humana, a razão é "incapaz" (incapable) de compreender tão bem seus próprios interesses, a exigência humiana de uma evidência histórica para a fundação contratual parece perambular pelos ares de modo ainda mais rarefeito que os exageros

\footnotetext{
${ }^{7} \mathrm{Ou}$ ainda, como concluirá no ensaio "Dos primeiros princípios do governo": "Procuremos estimar e melhorar o mais possível nosso antigo governo, sem encorajar qualquer paixão por essas perigosas novidades" (Ibid., p. 244). - rompe com a experiência, a tradição e o hábito políticos da época, que já não eram mais capazes de "persuadir" a opinião dos súditos. Uma insidiosa insurgência intelectual e popular se volta para a ruptura da situação política (ou, se se quiser, para a reemergência do estado de natureza que se desembainhava na ordem social).
} 
teóricos em que incorreu o dogmatismo contratualista dos inveterados entusiastas da razão (Ibid., p. 233). Por lançar a pá de cal sobre a condição natural dos homens, o filósofo racionalista concebeu abstrata e disruptivamente um quadro social erigido a partir de uma nova ordem política (ou uma "inovação violenta" condenada por Hume) muito mais real do que a do chefe militar humiano que impunha, sobre uma natureza humana assolada por tropeços casuais, o hábito da submissão pela força e pela "opinião de interesse" acerca das vantagens do governo.

Se a pretendida consistência do racionalismo contratual não resiste ao modo como Hume compreende originariamente a formação violenta dos governos, ainda assim a ideia de contrato se destaca da história, dando um salto sobre esse mundo de indivíduos habituados a viver sob o domínio de um líder. A evidência que se exige do contrato (por sinal historicamente não localizado) mostra, de sua parte, que a relação entre a ordem civil e o exercício da natureza humana é falível, o que, de fato, suprime a questão do consentimento do poder político (ou das condições sob as quais uma instituição política legitimamente se estabelece com perfeição). Tal poder, aos olhos de Hume, se dá pela evidência do exercício do governo e, através da força do hábito, pelo "sensivel benefício de sua influência", em que a autoridade se torna "querida pelo povo" conforme a permanência do "usurpador" lhe conferir, reconhecidamente, seu título de governante legítimo (Ibid., p. 236).

Mas mesmo que se abandonasse a hipótese acerca da origem do governo, tal como criticada por Hume, a noção de contrato, desprovida de qualquer base histórica, poderia permitir que se legitimasse a ideia da obediência dos súditos para com seu governante, não mais segundo a reverência naturalmente prestada 
àquele sob o poder do qual o indivíduo submisso veio ao mundo, mas pela tentativa de determinar até que ponto o povo se vê obrigado a obedecer à autoridade política. A disputa insuperável entre autoridade e liberdade, tensionada como vimos no ensaio "Da origem do governo", seria assim posta em novos termos, que para Hume não haveriam de parecer muito promissores. Esse novo devoto do contrato não explica o surgimento histórico do governo, nem busca, pela persuasão das paixões humanas, realçar a excelência moral do príncipe que, devido ao seu modo equilibrado de governar, autoriza a liberdade civil pela própria estabilidade de seu governo. Abrindo mão de um sentido histórico ou "natural", a concepção contratualista fundaria o governo ao instituí-lo por um decreto da razão.

\section{Referências bibliográficas}

HUME, D. Tratado da natureza humana. Trad. Déborah Danowski. 2 ed. São Paulo: Editora UNESP, 2009.

- Uma investigação sobre os princípios da moral. Trad. José Oscar de Almeida Marques. São Paulo: Editora da UNICAMP, 1995.

- A arte de escrever ensaios. Trad. Márcio Suzuki Pedro Pimenta. São Paulo: Iluminuras, 2011.

. "Da origem do governo", "Do contrato original", "Dos primeiros princípios do governo", "Da obediência passiva". Coleção: Os pensadores. Trad. João Paulo Monteiro Armando Mora D'Oliveira. 2 ed. São Paulo: Abril Cultural, 1980.

(ed.). Indianapolis: Liberty Fund, 1985.

KUNTZ, R. "Hume: a teoria social como sistema". In: Kriterion, Belo Horizonte, 124, dez. 2011, pp. 457- 490. 
PAUTRAT, B. "Du sujet politique et de ses interets: note sur la théorie humienne de l'autorité". In: Cahiers pour l'analyse ( La politique des philosophes), Cercle d'Epistémologie de l'École Normale Supérieure, jan. 1966, pp. 67-99. 
